\title{
Globalización, movilidad y análisis de conectividad aérea: una herramienta para la práctica interdisciplinar ${ }^{1}$
}

\section{Globalization, Mobility and Air Connectivity Analysis: a Tool for Interdisciplinary Practice}

\author{
Juan Antonio CÓRDOBA ORDÓÑEZ \\ Cándida GAGO GARCÍA \\ Departamento de Análisis Geográfico Regional \\ Universidad Complutense de Madrid \\ jcordoba@ghis.ucm.es \\ cgago@ghis.ucm.es
}

Recibido: 8 de enero de 2012

Aceptado: 28 de mayo de 2012

\section{Resumen}

Este trabajo explora la interconexión entre enfoques y metodologías procedentes de la Geografía y de la Antropología Social con vistas al estudio de fenómenos sociales y espaciales. Plantea cómo la utilización conjunta e informada de técnicas de investigación cuantitativas, como los análisis de conectividad área, y cualitativas, como el trabajo de campo etnográfico, resulta fundamental para el entendimiento de procesos de globalización socio-económica marcados por la movilidad. El estudio de la movilidad aérea en México revela la existencia de patrones de relaciones multi-escalares y multi-funcionales que son clave para explicar la dinámica de relaciones sociales y territoriales concretas en el contexto de la inserción mexicana en las políticas neoliberales. Concretamente, para analizar los impactos locales de reajustes en el ordenamiento regional, las migraciones laborales, el turismo, los procesos de desarrollo/subdesarrollo así como los procesos de uniformización y de hibridación cultural.

Palabras clave: geografía, movilidad, globalización, México, Península de Yucatán, transporte aéreo, diálogo interdisciplinar.

\begin{abstract}
This paper explores the interconnected relationship between Geography and Social Anthropology in the study of social and spatial phenomena. It argues that the informed and combined use of quantitative and qualitative research techniques, like air connectivity analysis and ethnographic fieldwork, are fundamental in the understanding of socioeconomic globalization processes, and particularly in those characterized by mobility. The study of air mobility in Mexico highlights the existence of multi-scalar and multi-functional patterns of relations that are vital to explain the situated dynamics of the social and territorial relations that have followed the country's adoption of neoliberal policies. And specifically, to analyze proces-

${ }^{1}$ Este trabajo forma parte de los resultados del proyecto de investigación CSO2011-26527 (Imaginarios y movilidades turísticas en tiempos de crisis) que desarrolla el Grupo de Investigación UCM-940614 (Territorio, Desarrollo y Cultura).
\end{abstract}


ses as regional adjustments, labour migration, tourism, development and underdevelopment, spatial fixation, as well as homogenization and cultural hybridization.

Keywords: geography, mobility, globalization, Mexico, Yucatan Peninsula, air transport, interdisciplinar dialogue.

Referencia normalizada: Córdoba Ordóñez, J. y Gago García, C. (2012) Globalización, movilidad y análisis de conectividad aérea: una herramienta para la práctica interdisciplinar. Revista de Antropología Social, 21: 117-146.

SUMARIO: 1. Introducción. 2. Globalización, movilidad y transporte aéreo. 3.Especificidades del escenario mexicano. 4. Análisis de conectividad aérea: una herramienta para la práctica interdisciplinar. 4.1. Cambios en la red doméstica. 4.2. Cambios en la red intercontinental. 4.3. Cambios en lared internacional.5. Movilidades y accesibilidadmejorada: el casodeYucatán. 6. Conclusiones. 7. Anexo de cuadros. 8. Referencias bibliográficas.

\section{Introducción}

Se argumenta con frecuencia que la creación y diferenciación de disciplinas ha obedecido tradicionalmente a la necesidad de fragmentar el conocimiento. Esta compartimentación lógica puede significar, sin embargo, un lastre cuando descubrimos que objetos y métodos disciplinares exclusivos (y/o excluyentes) no son suficientes para entender, aunque solo sea de forma parcial, la complejidad de los fenómenos que analizamos, aún más cuando estudiamos las dinámicas socio-espaciales inherentes a los procesos de globalización.

Coincidimos en este sentido con otras experiencias que señalan (i) que aunque el establecimiento de disciplinas pueda verse como un juego de fuerzas y poder, a veces nos damos cuenta de que no podemos responder a nuestras preguntas dentro de los limites de las propias disciplinas, por lo que debemos recurrir a las preguntas y las teorías de otras (Lelé y Norgaar, 2005); (ii) que, para comprender el proceso de la globalización, necesitamos ver el mundo en sus diferentes matices y en su interdependencia más que en compartimentos y actividades estancas (Schoenberger, 2001), una idea que sugiere un cambio de posicionamiento epistemológico motivado por los procesos de orden global (Escobar, 2008); y (iii) que el proceso de diálogo interdisciplinar puede ser una ocasión para la innovación y la creatividad (Moran, 2006).

En este artículo avanzamos un ejemplo de diálogo entre la geografía y la antropología social como parte de la cotidianeidad del trabajo y de la experiencia desarrollada dentro del equipo de investigación "Territorio, Desarrollo y Cultura: Teoría y práctica en la dialéctica Norte-Sur”. Este equipo está formado esencialmente por geógrafos pero en él también participan especialistas en antropología social, sociología, economía, ecología humana y biología. Uno de los objetivos fundamentales del equipo es el estudio de las dinámicas socio-espaciales inherentes a los procesos globales, y de forma más concreta, las relacionadas con la movilidad a diferentes escalas, siendo nuestros ámbitos prioritarios de trabajo España y México, país este último en el que se centra este trabajo. 
Concretamente, este artículo presenta un análisis de la conectividad aérea mexicana como una herramienta de reflexión que nos ha ayudado en la interpretación multi-escalar e interdisciplinar de las formas en que las regiones mexicanas y sus localidades se integran diferencialmente en el escenario mundial. Este análisis se revela como una herramienta particularmente interesante en el estudio de dos de los vectores cruciales de la globalización económica y socio-cultural: el turismo y las migraciones debidas a motivos laborales.

Los análisis de conectividad aérea han sido un campo de investigación confinado a la Geografía e, incluso dentro de ella, a tendencias de carácter esencialmente cuantitativo que estuvieron en boga durante los años 60 y 70 del siglo pasado dando lugar a trabajos consagrados como los de Hagget y Chorley o Taafe y Gauthier. A pesar de su indiscutible vocación neopositivista, en la mayoría de estos trabajos, las redes de comunicación se revelaron como instrumentos útiles para definir áreas de influencia y sistemas de relación social que ayudaron a romper con las dimensiones euclidianas convencionales del espacio, enfatizando la existencia de espacios relativos, construidos socialmente, cambiantes y en los que el tiempo era un componente fundamental. La mayoría de las ciencias sociales, sin embargo, no se han hecho eco de esta redefinición geográfica del espacio expresada en términos de compresión (Harvey, 1983), plasticidad (Forer, 1978) o aprehensión diferencial (Córdoba et al., 2007b). Actualmente, los estudios de redes conocen un nuevo impulso, siempre desde la Geografía, en relación con los procesos de globalización y en particular en relación con la existencia de sistemas de control y de organización a diferentes escalas. En nuestros estudios, los análisis de conectividad aérea han resultado muy útiles para establecer hipótesis de trabajo e incluso como apoyo interpretativo para comprender ciertos procesos y negociaciones socio-culturales que se establecen en los ámbitos locales de la etnografía y muy particularmente, en aquellos escenarios donde las movilidades motivadas por la migración y el turismo estructuran el día a día de la población.

El artículo se organiza en cinco apartados que contemplan sucesivamente (i) una reflexión sobre la interrelación entre la movilidad y el transporte aéreo en la perspectiva de los procesos globales, (ii) un acercamiento sintético a la singularidad geográfica del escenario mexicano, (iii) un análisis longitudinal de la conectividad del sistema de transporte aéreo de México en sus relaciones específicas con el sistema urbano del país, (iv) la presentación de algunos casos empíricos para la comprensión de los impactos de estos cambios macro-estructurales en prácticas locales en el caso de Yucatán y (v) unas conclusiones donde se argumenta la utilidad de este análisis como herramienta de reflexión interdisciplinar entre la geografía y la antropología social.

\section{Globalización, movilidad y transporte aéreo}

Se ha señalado que la movilidad es uno de los elementos discriminantes en un proceso de re-estratificación mundial mediante el cual se estaría creando una nueva jerarquía sociocultural a escala mundial (Bauman, 2001). La movilidad, en efecto, está profundamente relacionada con los fundamentos del concepto de globalización, 
entendida ésta de forma ecléctica como conectividad compleja (Tomlison, 2001), como intensificación de la interconexión a nivel mundial (McGrew, 1992) o genéricamente como una compresión espacio-temporal, tanto en el plano físico como en el simbólico (Harvey, 1998).

Varios estudios han señalado la movilidad y específicamente las movilidades turísticas, como el epítome perfecto de un mundo más interconectado que no sólo ha reemplazado al sedentarismo como modo de vida, sino que también lo ha hecho como una de las más meticulosas metáforas a través de la cual pensar lo social (Urry 2001; Larsen et al., 2006). El nuevo paradigma de la movilidad, planteado desde las ciencias sociales, enfatiza el carácter asimétrico de los patrones de movimiento y llama la atención sobre la necesidad de estudiar cuáles son los sistemas de movilidad, esto es, las infraestructuras sociales y materiales que hacen posibles o no los movimientos de personas, objetos, capitales e ideas (Urry, 2007). Uno de estos sistemas de movilidad es el transporte aéreo.

El transporte aéreo, interpretado tradicionalmente en claves de internacionalidad y de modernidad, ha favorecido el acercamiento de muchos centros periféricos a las regiones generadoras de riqueza, tanto en el ámbito nacional como a nivel mundial, y ha sido, además, un vector fundamental para proporcionar al turismo su protagonismo en el escenario contemporáneo de relaciones socio-económicas globales.

La creación de aeropuertos y de conexiones aéreas desde o hacia enclaves de la periferia y semi-periferias económicas, ha permitido la inserción de éstas en el sistema de relaciones globales, sea abriendo válvulas de escape para la emigración, sea atrayendo actividades y capitales y, en consecuencia, dinamizando centros que, durante las últimas décadas, han protagonizado la "des-localización" de actividades que, como el turismo, estaban antes muy acotadas en las latitudes templado-cálidas de los países desarrollados. En términos generales se acepta que los aeropuertos generan desarrollo porque facilitan la movilidad de bienes y sobre todo de personas y con éstas, de sus ideas y de su capacidad de trabajo y de consumo.

En Geografía, la movilidad generada por el transporte aéreo ha resultado ser un indicador muy valioso a la hora de valorar la centralidad y la organización y reestructuración de los sistemas urbanos, y se ha utilizado tradicionalmente para determinar intensidades de relación entre pares de ciudades a partir de las cuales se han realizado, posteriormente definiciones de jerarquías. Así, se ha constatado que las ciudades mejor situadas en las jerarquías de decisión (y de poder) a todas las escalas están siempre dotadas de aeropuertos y hasta hace poco tiempo el tráfico aéreo ha sido una de las pocas variables que ha permitido demostrar la existencia de redes de centros que organizan el territorio en las escalas de orden superior y particularmente en el ámbito global (Gago, 2003; Derudder y Wiltox, 2005).

Actualmente, la inserción de las localidades en las redes globales depende de la accesibilidad que los sistemas de conexión exterior proporcionan a los lugares, ya sea en forma virtual (internet) o física (transportes). Ocurre, sin embargo, que si bien las condiciones de accesibilidad virtual son cada vez más difusas, promoviendo procesos de homogeneización, las condiciones de accesibilidad física siguen siendo muy dependientes de unas infraestructuras materiales generalmente costosas y cuya 


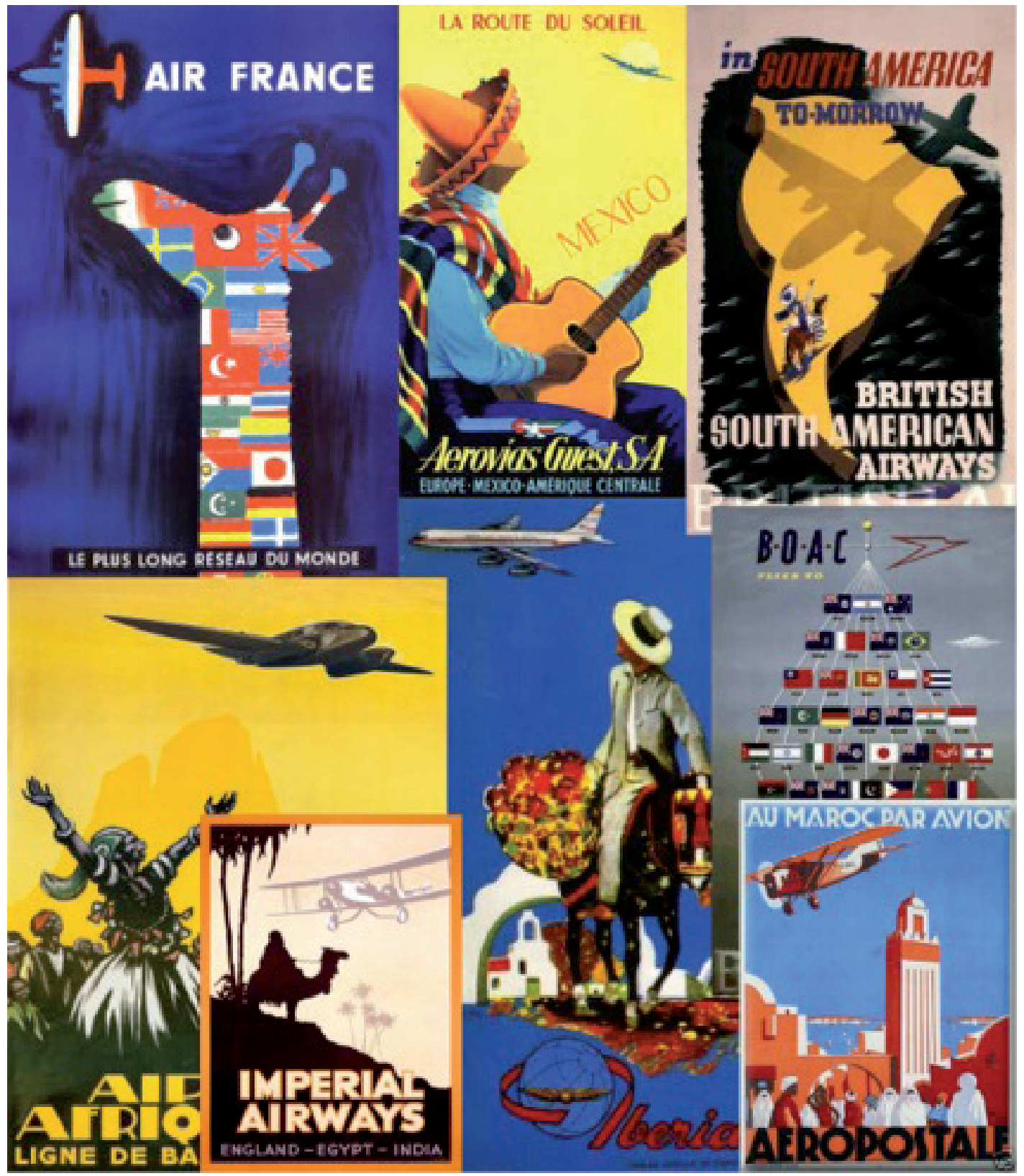

Figura 1. El cartelismo publicitario de las empresas de transporte aéreo documenta el recurso a los tópicos de la internacionalidad y del encuentro entre tradición y modernidad como reclamo. Carteles publicitarios de diferentes empresas de transporte aéreo entre los años 40 y los años 60 del siglo pasado. 
situación responde generalmente a una rentabilidad más económica que social. De esta forma, los aeropuertos, máximos representantes de la conectividad física exterior de los lugares, son un indicador sobresaliente de unas condiciones de accesibilidad diferencial que generan, inexcusablemente, formas de diferenciación espacial.

Los nexos entre la movilidad generada por el transporte aéreo y los procesos de globalización han intervenido sustancialmente en la reformulación, más o menos acertada, de conceptos que han emanado tanto desde la geografía como desde otras ciencias sociales, como la idea de "no-lugar" (Augé, 1995) y otros tales como "deslocalización" y "des-territorialización”. Entre estos conceptos, muchos de los cuales se nos antojan simples neologismos para re-definir viejos patrones de producción social del espacio, la idea de des-territorialización propuesta por García Canclini (1989: 229) como "pérdida de relación "natural" de la cultura con los territorios geográficos y sociales" es significativa cuando se advierte que el transporte aéreo "desnaturaliza" (desconecta de su espacio físico) las relaciones y actúa como agente en la formación de nuevas culturas, no determinadas específicamente por un territorio concreto.

Debido a la escala de las relaciones a las que afecta, el transporte aéreo es así capaz de generar nuevas identidades culturales asociadas a espacios de orden superior, al favorecer una re-territorialización (real, no virtual) de los espacios convencionales pero, aunque cristalice en dimensiones de orden superior, se trata de un fenómeno en el que vuelve a haber escalas, jerarquías y fragmentaciones que son simplemente facetas de una misma realidad: procesos asimétricos de diferenciación espacial creados por la movilidad.

En otro trabajo hemos sostenido que el transporte aéreo es uno de los elementos y vehículos clave de la civilización neo-técnica y que las nuevas condiciones de explotación del mercado, emanadas sobre todo de la liberalización del sector, están generando un nuevo concepto de vecindad más sensorial que geográfica, un fenómeno que estaría afectando a segmentos cada vez más amplios y transversales de la población, gracias a nuevas condiciones de movilidad y de accesibilidad (Córdoba et al., 2007a).

Uno de los mayores distribuidores de servicios turísticos del mundo y líder en el sector de las reservas de vuelos, ha destacado en uno de sus estudios de mercado, la creciente importancia del sector turístico en el transporte aéreo, estimando que se espera que lo utilicen más de 1500 millones de turistas en el horizonte 2020 (Amadeus, 2005). En este mismo informe se identifican las llamadas "principales tribus viajeras", formadas por los grupos que utilizarán en un futuro cercano este medio de transporte de manera creciente. Entre éstas, además de colectivos tradicionales como los altos directivos, los grupos más importantes serán los "profesionales itinerantes", los "mayores activos", una inusitada cantidad de personas de edad avanzada que se dedicarán a viajar por placer, y los "clanes mundiales", formados como consecuencia de los grandes flujos migratorios y de la cantidad creciente de familias diseminadas por diferentes países.

Hoy más que nunca, cuando "todo lo local" parece afectado por "lo global", son necesarias herramientas de trabajo y análisis interdisciplinares que permitan 
evidenciar cómo y por qué se produce esta interacción. En el encuentro de los estudios de geografía y de antropología que se ocupan de analizar las dinámicas socioespaciales asociadas a los procesos globalizadores, el transporte aéreo puede ser un indicador transversal significativo para el establecimiento de hipótesis y para el análisis fundamentado de determinadas servidumbres y patrones de circulación y/o fijación espacial relacionados con el turismo y las migraciones laborales, dos de los vectores de la movilidad global que sin duda más inciden en la nueva cotidianidad globalizada lo local.

\section{Especificidades del escenario mexicano}

Desde 1970 México ha entrado en una dinámica que ha transformado profundamente al país como consecuencia de su inserción en las grandes corrientes de cambio global. Una manifestación de estos cambios ha sido el crecimiento desorbitado de las actividades terciarias, de forma que en las últimas décadas el sistema productivo mexicano ha experimentado un fuerte giro hacia el sector de los servicios, que a finales de la primera década de este siglo absorbía ya a más de la mitad de la población trabajadora del país y generaba más del 70\% de los ingresos totales aunque en unas condiciones de productividad dudosamente "desarrolladas" (Coll y Córdoba, 2006).

La inserción de México en las corrientes globalizadores, acelerada con su integración en el TLC en 1991, ha tenido dos efectos casi inmediatos. Por un lado se ha propagado una oleada homogeneizadora en la que se han visto envueltas, ante todo, las macro-estructuras nacionales. Por otro lado, y como respuesta a esta homogeneización impuesta "desde arriba", se ha multiplicado la diversidad local en un proceso de heterogeneización que carece de precedentes en la historia del país. En relación con lo anterior, la interpretación de los fenómenos en la escala local en México debe tener en cuenta factores de naturaleza exógena que a menudo se encuentran o se gestan a muchos kilómetros de donde acaban incidiendo y esta incidencia de "lo global" en "lo local" está estrechamente relacionada con el desarrollo de unos sistemas de movilidad que, como veremos, dependen en buena medida de la accesibilidad de los centros a las infraestructuras aeroportuarias y a los sistema de conectividad exterior que éstos proporcionan.

Desde el punto de vista territorial, durante las últimas décadas, se ha producido en México un basculamiento general hacia el Norte, agravando el desequilibrio respecto a un Sur tradicionalmente deprimido y que cuenta con los indicadores de marginación y de pobreza más graves. La agudización de este desequilibrio territorial ha sido en parte imputable a la apertura de nuevos frentes de colonización agropecuaria en las tierras semiáridas del norte y en las tierras más húmedas del litoral pacífico; también ha intervenido en ello la difusión del sistema de maquiladoras que ha proporcionado una vitalidad económica especial a todos los estados de la frontera Norte. Pero junto a esta dinámica territorial que puede considerarse genéricamente "difusa", han existido otros focos de desarrollo económico que han tenido un carácter mucho más puntual y que se relacionan con la actividad petrolera en el Golfo y sobre todo con el turismo. 
Durante las últimas décadas del siglo XX, México se ha consagrado como uno de los grandes del turismo a nivel mundial. El turismo ha llegado a representar en 2009 el 8,9\% del PIB y el 6,9\% del empleo directo en el país (CPT, 2011). Gran parte de los 22,6 millones de turistas que entraron al país en 2011 y de los 11.700 millones de dólares estadounidenses que se imputaron a la actividad el mismo año (SECTUR, 2012) son resultado de unas políticas públicas de promoción e implantación turística que han dado su fruto convirtiendo a esta actividad en la tercera fuente de ingresos por detrás de la exportación de petróleo y de las remesas de emigrantes (Banco de México, 2011). Muchos agentes políticos, económicos y sociales mexicanos han apostado por el turismo como recurso alternativo para implementar el desarrollo de localidades e incluso de regiones y estados, abriendo las puertas de una nueva forma de dependencia exterior que se ha extendido, como una oleada modernizadora, por todo el país. En el otro lado de la moneda, los grandes agentes turísticos internacionales y sobre todo los turistas, se han visto atraídos por una oferta que ha abierto nuevos destinos, algunos de ellos prácticamente vírgenes, de gran riqueza patrimonial. En la confluencia de estas dos perspectivas, el turismo se ha convertido en México en un fenómeno social que ha transformado profundamente el modo de vida de muchas comunidades y hasta de regiones enteras que, como gran parte de la Península de Yucatán, se han convertido, en muy poco tiempo, en escenarios dependientes de los avatares del turismo a nivel global generando con ello nuevas servidumbres y vulnerabilidades (Bianet, 2010; Córdoba Azcárate, 2010).

Por otro lado, desde el punto de vista demográfico, y a pesar de que el crecimiento se ha ralentizado, la población de México se ha duplicado en los últimos 40 años, alcanzando los 112,3 millones de habitantes en 2010 (INEGI, 2011b). Durante este tiempo el proceso de urbanización se ha acelerado $(58,7 \%$ de la población en ciudades en 1970 y $77,8 \%$ en 2010) y se han producido reajustes en el sistema urbano nacional, con el traslado de las tasas de crecimiento más fuertes hacia las periferias metropolitanas de las grandes ciudades y hacia las ciudades medias y sobre todo hacia algunas muy concretas que han registrado crecimientos explosivos, particularmente en la frontera Norte (Tijuana 5,65\% y Ciudad Juárez 4,8\% anual en 1990-00) y sobre todo en enclaves turísticos (Playa del Carmen 17,0\%; Cancún 7,8\% y Puerto Vallarta 7,0\% en 2000-05) (INEGI, 1991; 2001 y 2006). Este crecimiento demográfico selectivo es la expresión de una reorientación de los flujos migratorios internos hacia los nuevos motores del desarrollo nacional o al menos hacia las nuevas fuentes de esperanza para el mercado laboral. Con todo, la emigración hacia el exterior ha seguido siendo la gran válvula de escape que ha aliviado las tensiones sociales generadas por la violencia y velocidad de los cambios económicos: un informe de la Universidad de Berkeley estimaba que en 2006 vivían en Estados Unidos 30 millones de habitantes de origen mexicano, 12 millones de ellos de primera generación (Wallace y Castañeda, 2006). Otro informe, de la oficina censal estadounidense, estimaba que en 2002, el 66,9\% de la población hispana residente en Estados Unidos era de origen mexicano (Ramírez y de la Cruz, 2003) y un tercer informe, de la Cámara Mexicana de Diputados, estimaba que entre 1970 y 2003 habría emigrado un total de 8,2 millones de mexicanos hacia el país vecino (Reyes, 2008). 
Turismo y migración se presentan así como dos de los pilares macro-estructurales que sostienen los cambios que han ocurrido en el país durante las últimas décadas y ambos son formas de movilidad en gran medida dependientes de las condiciones de accesibilidad que proporciona al territorio el transporte aéreo.

Las características geográficas de México hacen al país proclive a este tipo de transporte. Además de una extensión considerable (casi 2 millones de $\mathrm{km}^{2}$ ), las condiciones naturales (áreas de montaña y los ámbitos tropicales) han dificultado mucho el desarrollo de las vías superficiales de comunicación convirtiendo al avión en un instrumento importante para el desenclave, incluso en distancias muy cortas. En 2010, se contabilizaban en México un total de 1465 instalaciones aeronáuticas (INEGI, 2011a) y los 76 aeropuertos con tráfico comercial registraron un movimiento total de 77,6 millones de pasajeros, $35,9 \%$ de ellos en movimientos internacionales lo que expresa, ante todo, la importancia del transporte aéreo en el sistema de relaciones exteriores del país.

Atendiendo solamente al tráfico de pasajeros, la jerarquía aeroportuaria expresa muy bien el papel destacado de la capital del país, que absorbe el $30 \%$ del tráfico aéreo mexicano y de las dos metrópolis nacionales de equilibrio, Guadalajara y Monterrey, con aproximadamente un 15\% del tráfico total. Sin embargo, más allá de estos dos niveles en la jerarquía, no se puede establecer una correlación satisfactoria entre el tráfico aéreo y la posición de las ciudades en el sistema urbano. Un simple diagrama de dispersión refleja muy bien que la importancia de las ciudades dentro la jerarquía urbana y su presunto peso correlativo en la economía nacional no explican satisfactoriamente las características del tráfico aéreo mexicano (ver Figura 2) lo que, expresado en otros términos, viene a significar que el transporte aéreo satisface en México tipos específicos de demanda, entre ellas el turismo y la migración.

El desarrollo a gran escala de las actividades turísticas, uno de los elementos impulsores de la difusión de las infraestructuras aéreas en México, se ha convertido en una expresión tangible de las tensiones entre las fuerzas globales homogeneizadoras y la heterogeneidad de las respuestas locales que apuntábamos anteriormente. El impacto local del turismo en México ha sido, hasta el momento, extraordinariamente diverso debido, en parte, a la variedad de formas en que se ha implantado la actividad (turismo de sol y playa, turismo de naturaleza, turismo cultural, turismos alternativos, etc...), pero debido también a las diferentes formas en que las localidades han recibido y dado respuesta al fenómeno (resistiendo su implantación, trabajando como mediadores en su desarrollo o estando al margen del mismo). Además, la mejora en las condiciones de accesibilidad y las transformaciones de un mercado socio-profesional obsoleto que ha promovido el turismo han reconducido en ciertas regiones los flujos migratorios y ello al menos en un doble sentido: unas veces conteniendo la sangría de la migración exterior, otras veces abriendo una vía de escape a esta misma emigración en ámbitos que antes estaban prácticamente preservados. Estos dos procesos se han dado, por ejemplo, de forma sucesiva en el ámbito de la península de Yucatán: la creación del polo turístico de Cancún en 1975 y el posterior desarrollo de la Riviera Maya crearon un poderoso mercado de trabajo regional que fomentó el éxodo rural hacia estas áreas. Una vez instalada la "cultura de la 
emigración" en el medio rural yucateco, el éxodo empezó a afectar a ámbitos cada vez más aislados y a dirigirse hacia destinos cada vez más diversificados y lejanos, entre ellos EE.UU. Estos hechos son muy importantes para interpretar muchos de los cambios que se han producido en la esfera local y deberían ser tenidos en cuenta a la hora de realizar etnografías o estudios de caso desde una perspectiva antropológica ya que pueden condicionar la posibilidad misma de aparición o de bloqueo de ciertas formas de preeminencia o de relaciones sociales, desde el mismo encuentro cara a cara de anfitriones y de turistas, hasta la emergencia de emprendedores o de nuevos sistemas de poder local, la reestructuración de redes familiares o el surgimiento de nuevas formas de familia, entre otras.

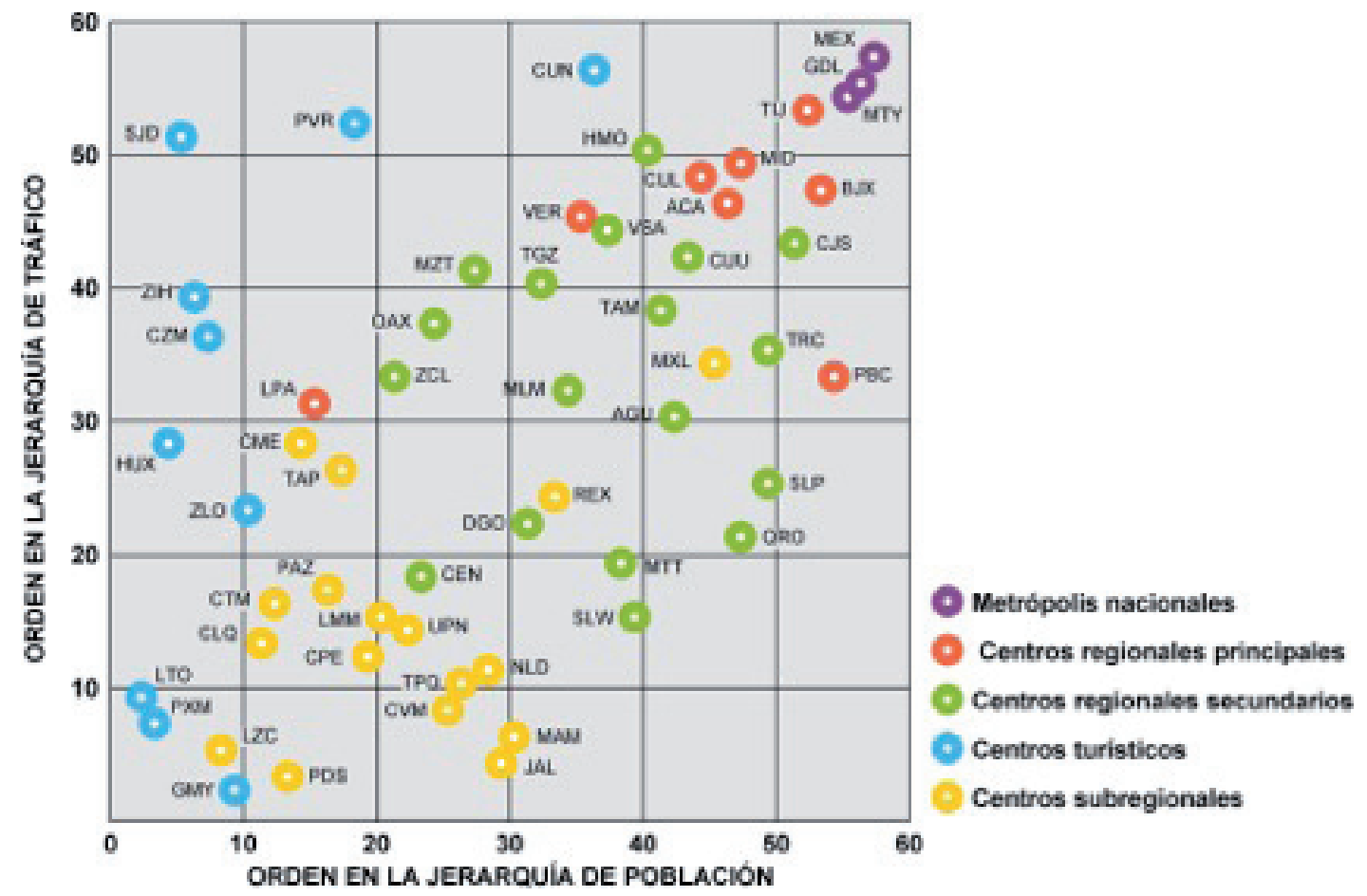

Figura 2. Diagrama de dispersión donde se relacionan el orden en la jerarquía del sistema urbano según la población de las localidades y el orden en la jerarquía aeroportuaria según el tráfico total en 2008.

\section{Análisis de conectividad aérea: una herramienta para la práctica interdisciplinar}

La Geografía tiene una larga y fructífera trayectoria en estudios que versan sobre el significado de los centros urbanos en los sistemas de relación social y territorial. Desde los años 90 del siglo XX han sido numerosos los estudios que atienden, en el contexto de la globalización, a la inserción de las ciudades en redes, a través de sus condiciones de conectividad (real y virtual), para mostrar la preeminencia de 
unos centros sobre otros. Un trabajo reciente de Derudder (2006) ha sintetizado las aportaciones y los enfoques que se han realizado hasta la fecha sobre el concepto y la identificación de una jerarquía urbana de escala global y las diferentes funciones desempeñadas por las ciudades en contextos de globalización así como la utilidad de las metodologías cuantitativas en este tipo de análisis. Este autor ha subrayado la importancia de las aportaciones de Friedmann $(1986 ; 1995)$ y Taylor $(1997 ; 2004)$ o él mismo (Derudder et al., 2003), y el concepto de ciudad mundial sostenido por Sassen. Los primeros han sostenido que las ciudades son centros de control y dirección, no ya solo económico, sino también geopolítico y simbólico y que en un contexto de división internacional del trabajo, la inequidad espacial se agudiza debido a la concentración de ventajas en un número limitado de centros, entre ellas la dotación en infraestructuras aeroportuarias. Por su parte, la hipótesis de Sassen $(1991 ; 2001)$ ha revelado que los flujos y los intercambios que se producen en el contexto de la globalización rompen la tradicional división entre Norte y Sur, quedando las ciudades que se insertan en los procesos de globalización cada vez más desconectadas de sus hinterlands.

Estas ideas resultan interesantes cuando se contemplan los cambios experimentados por la conectividad aérea del sistema urbano mexicano y para ahondar en estas cuestiones hemos recurrido a una metodología cuantitativa sencilla, contrastada en otros trabajos de investigación (Córdoba y Gago, 2011) y que forma parte de un corpus metodológico ampliamente utilizado en la geografía del transporte como es el análisis longitudinal. Para ello hemos utilizado datos de 1970, 1991 y 2008, referidos a los vuelos que pueden considerarse regulares, contemplando la totalidad de las relaciones en el ámbito internacional y solamente los vuelos directos (entre pares de ciudades) en el ámbito doméstico. Las fuentes de información fundamentales han sido las guías $A B C$ World Airways para 1970 y 1991 y la base de datos $O A G$ Aviation que comercializa OAG-UBMA para el año 2008.

Para este análisis hemos recurrido a una medida sencilla de conectividad topológica, el coeficiente de conexión (CK) que evalúa la conectividad real de un nodo - las relaciones reales de ese nodo - con respecto a la conectividad potencial de ese nodo, esto es el número de nodos susceptibles de estar conectados con él, siendo éstos todos los nodos que forman parte del sistema considerado menos él mismo y aquéllos que están demasiado cerca como para que se establezca una relación aérea entre ellos. El CK puede entenderse como un simple porcentaje de forma que $\mathrm{CK}=100$ quiere decir que hay una conexión total y $\mathrm{CK}=50$ indica que existe la mitad de las conexiones posibles.

\subsection{Cambios en la red doméstica}

El análisis detallado de los cambios que ha experimentado la red interior de transporte aéreo en México desde 1970 sería demasiado prolijo para este artículo. Por ello nos limitamos a expresar algunos de los aspectos más relevantes que se han derivado de la investigación:

- Ante todo se debe resaltar el incremento en el grado de cohesión de la red, desde 6,75 en 1970 hasta 25,02 en 2008. 
- Durante este tiempo se ha reforzado el liderazgo de Ciudad de México en el sistema, con un CK que se eleva desde 59,65 en 1970 a 80,95 en 2008 y que informa sobre el papel hegemónico reforzado que desempeña esta ciudad en el sistema de comunicaciones aéreas del país, una idea que contraviene la presunción de que México ha conocido un serio proceso de descentralización que sería reflejo de la modernización del país a partir de los años 80 del siglo XX.

- También durante este tiempo se ha confirmado el papel hegemónico de las grandes metrópolis de equilibrio nacionales, Guadalajara (CK de 23 a 34) y Monterrey (CK de 25 a 28).

- El hecho más llamativo de los cambios experimentados durante este lapso de tiempo lo representa el contraste en el comportamiento de los nodos de las regiones septentrionales y meridionales del país. Aunque hay que tener en cuenta que parte de este comportamiento diferencial obedece a una sensible mejora en las comunicaciones superficiales, resultan especialmente llamativos la relevancia acrecentada del transporte aéreo en el ámbito del Mar de Cortés (las dos Californias, Sonora y Sinaloa) que se ha convertido en un nuevo frente de colonización económica del territorio, sobre todo en materia de turismo, el vitalismo de la Frontera Norte y el estancamiento de los nodos de las regiones Sur y Sureste.

- Existe, por último, al menos otro hecho significativo que informa sobre cambios en la movilidad potencial generada por el transporte aéreo: el dinamismo de ciertos centros regionales de actividad económica y de centros que son, sin duda, plataformas internas de movilidad para regiones de intensa emigración. Entre los primeros destacan nuevos nodos con marcada funcionalidad turística y que han irrumpido en el sistema aéreo con fuerza (Los Cabos y Cancún) o nodos que empiezan a desbrozar nuevos ámbitos de colonización turística (Puerto Escondido y Huatulco). Entre los segundos pueden tipificarse Morelia y Zacatecas, aunque probablemente también León, Puebla y Durango.

\subsection{Cambios en la red intercontinental}

El análisis de la conectividad internacional de México ha permitido constatar la creciente apertura de México hacia el exterior en el marco de un sistema que está esencialmente polarizado por Estados Unidos. La conectividad exterior de México se ha incrementado de una forma espectacular entre 1970 y 2008 (ver Cuadro 1) Las ciudades mexicanas que participan en el sistema exterior de relaciones en 2008 son, además de las grandes metrópolis regionales y los principales centros turísticos del país, la mayoría de los principales centros regionales e incluso algunas ciudades funcionalmente especializadas.

Aunque las relaciones de México con el ámbito latinoamericano se han incrementado, han perdido peso en el conjunto de las relaciones exteriores de México siendo significativo además que el número de centros conectados ha descendido de 25 en 1970 a 16 en 2008. Los cambios en la direccionalidad expresan muy bien que México ha perdido su carácter de bisagra en el sistema de relaciones interamericano, un hecho que debe relacionarse ante todo con las nuevas características del 
transporte aéreo, mucho más dado ahora a las relaciones directas sin escala, favorecidas no solo por la autonomía de las aeronaves sino también por el incremento de la demanda de tráfico punto a punto y que ya no justifica los vuelos por etapas que tenían por objeto completar coeficientes de carga. En esta pérdida hay que ver también, sin embargo, un retraimiento en la capacidad internacional de liderazgo de México, asociada sin duda a la incapacidad para utilizar la centralidad como un factor de desarrollo nacional y regional. De esta forma, por ejemplo, el potencial que ofrecía en 1970 una ciudad como Mérida en Yucatán para convertirse en una metrópoli en el ámbito centroamericano ha desaparecido por completo en 2008 . Y en este mismo sentido, durante este periodo, Panamá ha acaparado una función de plataforma giratoria en el sistema de relaciones interamericano que muy bien podría haber desempeñado Ciudad de México (ver Cuadro 2).

Por su parte, aunque la relevancia de Europa en la relaciones exteriores mexicanas ha crecido, sigue muy lejos del peso que tienen las relaciones con Estados Unidos. Finalmente y como manifestación de un sistema de inserción global polarizada, México ha mantenido su desconexión con el mundo africano y una muy débil conectividad con el ámbito Asia-Pacífico.

Uno de los aspectos más reveladores de este análisis es la definición de Ciudad de México como cabeza no solo del sistema mexicano de relaciones internacionales sino de todo el sistema latinoamericano (ver Cuadros 2 y 3). Tanto en 1970 como en 2008 se ha confirmado que Ciudad de México, seguida por Sao Paulo y Buenos Aires son las cabezas indiscutibles de un subsistema latinoamericano y sus principales conectores con los procesos globales como han señalado otros trabajos (Gilbert, 1998; Consony y Taylor, 2007). Esta triada, sin embargo, formaría parte de un escalón secundario de ciudades en una jerarquía de centros mundiales rectores, como han apuntado otros autores (Córdoba y Gago, 2002; Taylor et al., 2011).

\subsection{Cambios en la red internacional}

Dentro del sistema internacional específicamente mexicano, la capital ostenta el coeficiente de conexión más elevado pero, a diferencia de lo que ocurría en el ámbito doméstico, su grado de centralización ha disminuido sensiblemente en la medida en que se han sumado al sistema de relaciones exteriores de México numerosos centros extranjeros que solamente están conectados con los destinos turísticos mexicanos.

Cancún, en el Caribe mexicano, convertido ya en el segundo aeropuerto del país tanto por su volumen de tráfico como por un coeficiente de conexión internacional que se acerca mucho al de la capital, es un ejemplo perfecto de la polarización que han introducido en México los fenómenos globales como consecuencia de la implantación de nuevas infraestructuras aéreas. El ascenso de este centro en la jerarquía de nodos latinoamericana ha sido espectacular y está estrechamente relacionado con el auge del turismo en la Riviera Maya pero también con otro fenómeno de mayor amplitud geográfica como ha sido la emergencia de focos turísticos caribeños de proyección mundial (Punta Cana o Montego Bay, por ejemplo) y que expresan cómo el turismo está siendo un elemento de primer orden en la internacionalización de 
algunos ámbitos latinoamericanos. Numerosos trabajos han analizado la evolución y la originalidad de Cancún desde diferentes perspectivas sociales, pero la mayoría de ellos se han limitado a contemplar a esta ciudad como un producto artificial del turismo, una "Gringolandia" (Torres y Momsen, 2005) típicamente representativa de los no-lugares gestados por la globalización. La relevancia internacional de Cancún que se desprende de nuestro trabajo apunta, sin embargo, hacia planteamientos más profundos y sugerentes que enlazarían con la idea de la re-localización de centros productivos en la escala mundial asociada a los nuevos patrones de movilidad generados por la globalización. En este sentido, cabe pensar que Cancún es ahora la nueva imagen mundial de la modernidad mexicana que ha arrinconado al obsoleto y decadente Acapulco, verdadero icono del turismo mundial y del propio México en los años 60 del siglo pasado (Córdoba et al., 2007b).

Por su parte, entre 1970 y 2008, las dos grandes metrópolis mexicanas de equilibrio nacional, Guadalajara y Monterrey, han incrementado su peso en el sistema de relaciones exteriores de México expresando una mayor integración, si no global, al menos macro-regional ya que ambas muestran claramente la polarización que ejerce sobre ellas Estados Unidos.

Además de los centros antecitados, los cambios más importantes que se han producido en el sistema de relaciones exteriores de México entre 1970 y 2008 se puede sintetizar en algunos rasgos específicos (Cuadro 4), como una participación creciente y decisiva de los centros turísticos aunque con diferencias entre ellos, el protagonismo que adquieren centros funcionalmente especializados, sobre todo en relación con el petróleo, (Tampico, Veracruz y Villahermosa), el papel de determinados centros en la reorganización regional y, por último, la configuración de plataformas de la emigración mexicana hacia Estados Unidos, (Morelia, Oaxaca, Zacatecas o Durango).

En este sentido, el papel decisivo que estaría desempeñando la emigración hacia Estados Unidos en los nuevos patrones de la movilidad exterior mexicana se refuerza con el análisis de la direccionalidad de los flujos desagregada a nivel de centros de correspondencia en el extranjero (ver Cuadro 5). Las áreas metropolitanas de Los Ángeles, Chicago y Dallas/Forth Worth que albergan los contingentes más elevados de mexicanos censados en Estados Unidos son también los centros que tienen una mayor diversificación de vuelos y una mayor intensidad de frecuencias hacia México (ver Cuadro 6 y Figura 3). A ellos se suman otras áreas metropolitanas en las que, según los datos oficiales, residen numerosas colonias de mexicanos como San Francisco, San José, Fresno y San Diego en California, Las Vegas, Phoenix, Denver, San Antonio, Atlanta y Nueva York y, sobre todo, Houston, donde se estima que viven más de medio millón de mexicanos de origen censados (Batalova, 2008).

A pesar de que los datos sobre la emigración mexicana hacia Estados Unidos son muy incompletos, estas conectividades específicas permiten sostener con firmeza la estrecha relación entre el transporte aéreo mexicano y la emigración por motivos laborales. El acceso de los migrantes al transporte aéreo y la movilidad y alcance que de ello derivan es una cualidad de caracteriza a los grandes flujos migratorios de finales del siglo XX, a diferencia de los movimientos masivos de población 


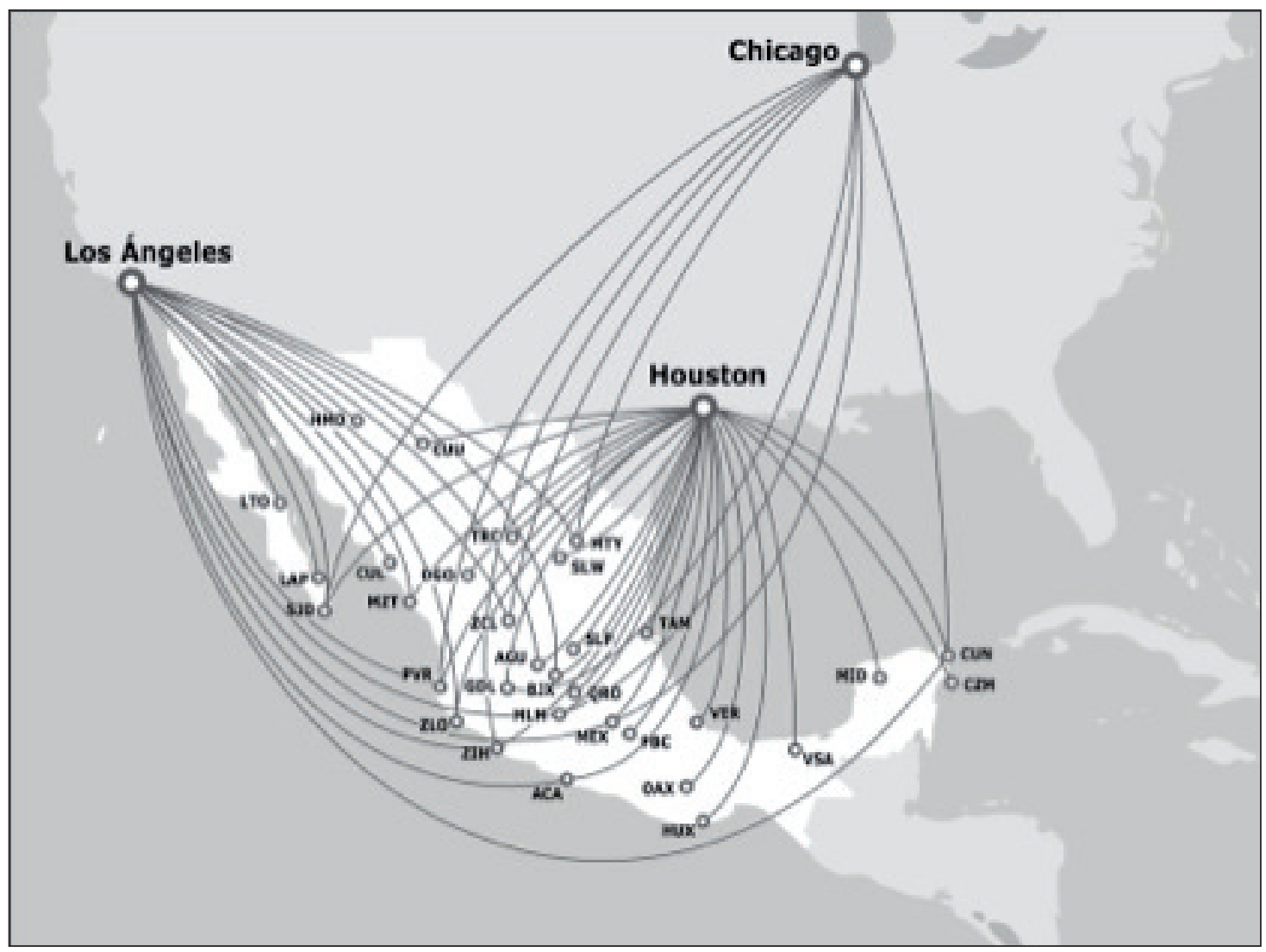

Figura 3. Direccionalidad de las conexiones hacia México desde Houston, Los Ángeles y Chicago, tres las zonas metropolitanas de Estados Unidos que cuentan con mayor número de residentes nacidos en México.

precedentes. En este sentido, la vecindad de un aeropuerto se ha convertido en un factor que no solo facilita las migraciones sino que las potencia psicológicamente en relación con la idea de la "vecindad sensorial", ya aludida en este trabajo.

Las relaciones entre los patrones de movilidad aérea (direccionalidad y frecuencias) y los de los flujos migratorios y turísticos (orígenes/destinos) parecen claros, de forma que puede inferirse que una parte considerable del tráfico aéreo mexicano está motivada por el turismo y la migración complementando a otra demanda, más elitista, que se ha considerado siempre la clientela dominante del transporte aéreo (profesionales, clases desahogadas).

En el ámbito del turismo esto no es nuevo: el turismo se ha convertido en una parte muy significativa del tráfico aéreo mundial en la misma medida en que el avión ha promovido la difusión de las actividades turísticas; muchos destinos turísticos en todo el mundo han basado su éxito precisamente en el apoyo que les ha prestado la infraestructura aeronáutica dotándoles de una accesibilidad competitiva. 
En el ámbito de las migraciones, en cambio, es donde se revelan nuevas ideas si pensamos que el trasporte aéreo, gracias a su democratización, está favoreciendo la consolidación de flujos de carácter permanente entre lugares de origen y destino permitiendo el afianzamiento de esos "clanes familiares" de los que habla el antecitado informe Amadeus. Estos clanes constituyen nuevas formas de interacción social que, con la globalización, están adquiriendo dimensiones no solo internacionales sino también intercontinentales y tal vez globales: son los emigrantes que retornan en vacaciones o con motivo de las fiestas locales, los familiares que visitan a los emigrados, los amigos de unos y de otros que aprovechan redes físicas de acogida y de experiencia materializando lazos que se fortalecen con las nuevas redes virtuales. En numerosos trabajos de campo realizados en el sur de México con colegas antropólogas hemos podido constatar la existencia de estas nuevas pautas en la movilidad y a veces en localidades recónditas a las que la relativa cercanía a un aeropuerto proporciona una accesibilidad mejorada que era impensable hace solo unos años.

\section{Movilidades y accesibilidad mejorada: el caso de Yucatán}

La península de Yucatán, donde nuestro equipo de investigación lleva realizando sistemáticamente trabajo de campo desde 1992, es el escenario donde hemos podido constatar la necesaria imbricación entre la geografía y la antropología a través de la interconexión entre el turismo, la emigración y unas condiciones de accesibilidad mejorada.

Sumida en una crisis de dimensiones dramáticas como consecuencia del desmantelamiento del sistema henequenero a principios de los años 80 del siglo XX, Yucatán entró, casi de la noche a la mañana, en un proceso de modernización forzada que ha convulsionado todos sus sistemas de relaciones productivas y sociales provocando además un profundo reajuste en la distribución peninsular de la población y en la organización del sistema urbano. Una de las respuestas demográficas a esta situación fue la generación de un éxodo rural tardío que alimentó primero el crecimiento urbano y más tarde la emigración exterior. Carente de recursos naturales de interés comercial y sin industria, la reconversión productiva de Yucatán ha tenido que fundamentarse necesariamente en nuevas alternativas. Entre éstas, las actividades terciarias - como tantas veces en tiempos de crisis - se convirtieron en el sector refugio generando una oleada de éxodo rural que se dirigió ante todo hacia la capital regional, Mérida, y hacia las otras capitales estatales y algunas pequeñas cabeceras comarcales (Valladolid, Tizimín, Ticul...). Entre estas actividades terciarias, sin embargo, el turismo se convirtió pronto en la verdadera tabla de salvación regional.

Concebido por el gobierno federal como un centro integralmente planificado para el turismo, Cancún se creó en 1975 sobre un pueblo que tenía 100 habitantes en 1970. Actualmente la ciudad supera los 700 mil y empieza a disputar la primacía regional a Mérida. Pero lo más importante es que Cancún ha sido el punto de partida (el "proyecto detonador" en palabras de sus gestores) de una región turística, la Riviera Maya, que actualmente ocupa un frente costero de más de $120 \mathrm{~km}$ lineales y que constituye el centro de atracción turística más importante de toda la cuenca 
del Mar Caribe (casi 50 mil cuartos de hotel y 6 millones de visitantes en 2011). Aunque el crucerismo es hoy día una forma de acceso importante para el turismo de la Riviera Maya (3,6 millones de pasajeros en 2010), la explosión turística de esta región sería inconcebible sin el aeropuerto de Cancún, que con un tráfico anual superior a 12 millones de pasajeros es el segundo en importancia del país y uno de los más importantes de Latinoamérica.

Cancún y la Riviera y el turismo asociado a ellas han sido responsables de la organización de los flujos migratorios yucatecos durante los últimos 20 años. Flujos alimentados, ante todo, por una población poco cualificada y necesitada de un trabajo remunerado que han proporcionado las propias actividades turísticas, muchos servicios asociados y la construcción. Movimientos con una pendularidad característica que permitía a los trabajadores, sobre todo al principio, regresar a sus pueblos los fines de semana para ayudar en las tareas locales y visitar a los hijos dejados al cuidado de los abuelos. Desde la creación de Cancún y, sobre todo desde los años 80 , la emigración se convirtió en una de las fuentes de ingresos fundamentales en la economía de Yucatán y, sobre todo, en una de las "salidas laborales" más importantes para los jóvenes. Durante los primeros años de la crisis henequenera, los flujos migratorios se dirigieron sobre todo hacia los centros turísticos de la costa, ávidos en mano de obra: en la mayoría de las unidades familiares, al menos uno de los miembros trabajaba en "Cancún". Pero más tarde, a medida en que los propios desarrollos turísticos empezaron a saturar su mercado laboral y cuando la "cultura migratoria" había alcanzado a las localidades más recónditas, los flujos empezaron a dirigirse hacia otras áreas del país y sobre todo hacia Estados Unidos donde se calcula que actualmente ya residen más de 180.000 yucatecos (Diario de Yucatán, 2011): algunos de ellos utilizaron Cancún, la Riviera y Mérida como primera escala del proceso migratorio; hoy muchos emigrantes se dirigen ya "sin miedo" directamente desde el pueblo hacia el país vecino.

Entre muchos otros casos constatados de accesibilidad mejorada en trabajo de campo nos gustaría recordar el de un joven de 17 años, Nicolás, habitante de Xul, una localidad de 100 habitantes situada en el corazón de la península de Yucatán. Nicolás viajó para visitar a sus hermanos mayores en Seattle (estado de Washington) donde se quedó más tiempo del que había pensado en un principio "para ayudar" a "cortar árboles". Por desgracia, el joven cayó "desde muchos metros, fracturándose la espalda". Después de "ser atendido por el servicio de urgencia" ( $i$ ?) y gracias a "una derrama entre amigos" ( $i$ ? ) logró repatriarse en avión para volver a casa de sus padres donde empezaba a restablecerse. Nicolás, que era hijo del cacique local, accedió voluntarioso a nuestra entrevista luciendo en el cuello una cadena de oro espectacular y confesó estar aburrido y deseando volver a cortar árboles "aunque mejor en Canadá, donde dan más dinero".

Otro caso de vecindad sensorial fundamentada en el transporte aéreo es el de Miguel, de 23 años, vecino de Mocochá, un pueblo de la antigua región henequenera, próximo a Mérida. Recién terminada la "preparatoria" (bachillerato), con 18 años, Miguel fue a trabajar a Cancún en la hostelería desde donde regresaba todos los fines de semana para ayudar a su padre con el autotransporte. Para Miguel, Cancún 
fue un hito en su proceso migratorio que le permitió una cierta profesionalización ("allí aprendí contaduría..." ¿?) y una mejora en su dominio del inglés ("servía de intérprete entre el dueño y los suministradores..."), antes de dar el salto a Houston donde actualmente trabaja en el "negocio de los carros" ( $¿$ ?). Su madre, doña Jacinta, empleada doméstica en Mérida, asegura que las remesas de su hijo mayor han sido fundamentales para la formación de su hermana, que trabaja como secretaria también en Mérida y sigue viviendo en el hogar familiar "y no se ha tenido que ir a trabajar a Cancún que no es buen lugar para una mujer joven". Ella no lamenta la lejanía de su hijo porque "todos los años regresa [en avión] para las fiestas del pueblo" y porque "allí está mejor que en Cancún donde no ganaba mucho, donde era muy caro y no era seguro y desde donde tenía que venir de seguido para ayudar y regalar a su papá [autotransportista] unos pesos".

Las evidencias de la inserción de los pueblos yucatecos en el sistema global de relaciones son muchas y van siendo conocidas gracias al trabajo de numerosos antropólogos y a la práctica de arduos métodos etnográficos. Pero estas evidencias son apreciables también a través de los cambios en la morfología del paisaje rural. Por ejemplo, a través de la aparición de ciertos servicios-testigo como los "ciber" y las agencias de cambio de moneda (en un medio desprovisto de sucursales bancarias) y, sobre todo, por medio de la progresiva sustitución de la vivienda vernácula (en adobe y con techo de palma) por edificios con estructura similar, construidos siempre dentro del solar familiar, pero en "tabicón y concreto" (cemento) y con estética "a la americana" (porches cubiertos, columnatas y balaustradas, superficies acristaladas y a veces dos pisos) (Ver Figura 4).

Entre estas ¿"aberraciones"? morfológicas nos viene a la mente una "superbodega" sita en Oxcutzcab (Figura 5), el mercado de frutas más importante de la llamada región frutícola situada al pie de la Sierrita, en el sur del estado de Yucatán. El almacén, erigido solo a unas manzanas del mercado local, cumple también las funciones de supermercado y de agencia financiera, ocupa toda una manzana del pueblo, está construido en hormigón y luce en su fachada un tremendo mural pintado a mano donde se reproduce el puente de San Francisco sobre la bahía homónima: todo un espectáculo visual en mitad de la "selva".

La fenomenología de la migración yucateca empieza a conocerse gracias a trabajos relativamente recientes, algunos de los cuales ya ponen énfasis en los clanes transfronterizos y la formación de redes virtuales al amparo de la comunidad yucateca residente en Estados Unidos y que es especialmente considerable en San Francisco y en Los Ángeles (Be, 2011; Solís y Fortuny, 2010). Algunos de estos trabajos apuntan ya hacia el papel decisivo que desempeña el transporte aéreo durante el episodio migratorio (Cornejo y Fortuny, 2012) pero ningún trabajo que nosotros conozcamos contempla aún su protagonismo en el sostenimiento de las redes y los lazos familiares bien sea a través de las visitas familiares o de los retornos temporales, algo fundamental para estudiar la materialización de lo que anteriormente denominamos como esa "cultura de la emigración". Solamente el trabajo de Figueroa (2009) nos pone en la pista de que los emigrantes consolidados en EE.UU. y que ya 


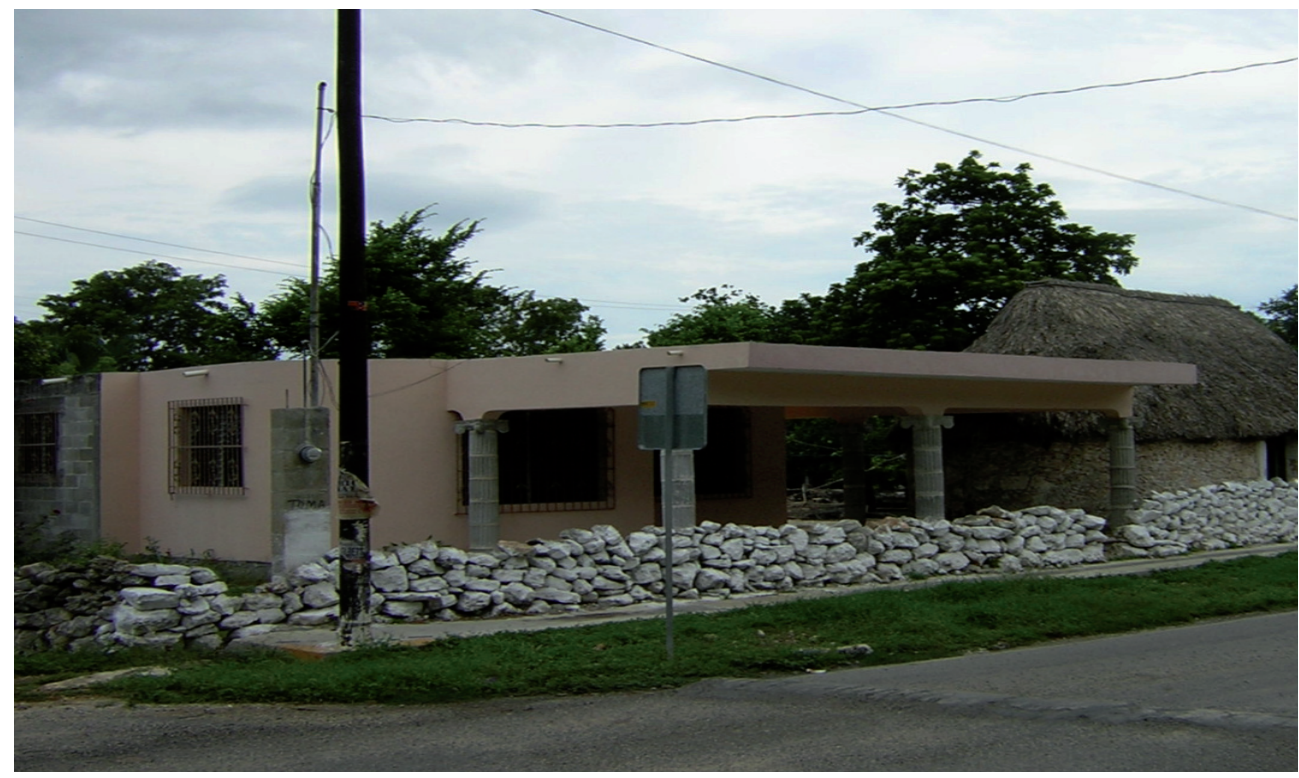

Figura 4. Un solar familiar donde conviven casa de adobe y casa de cemento

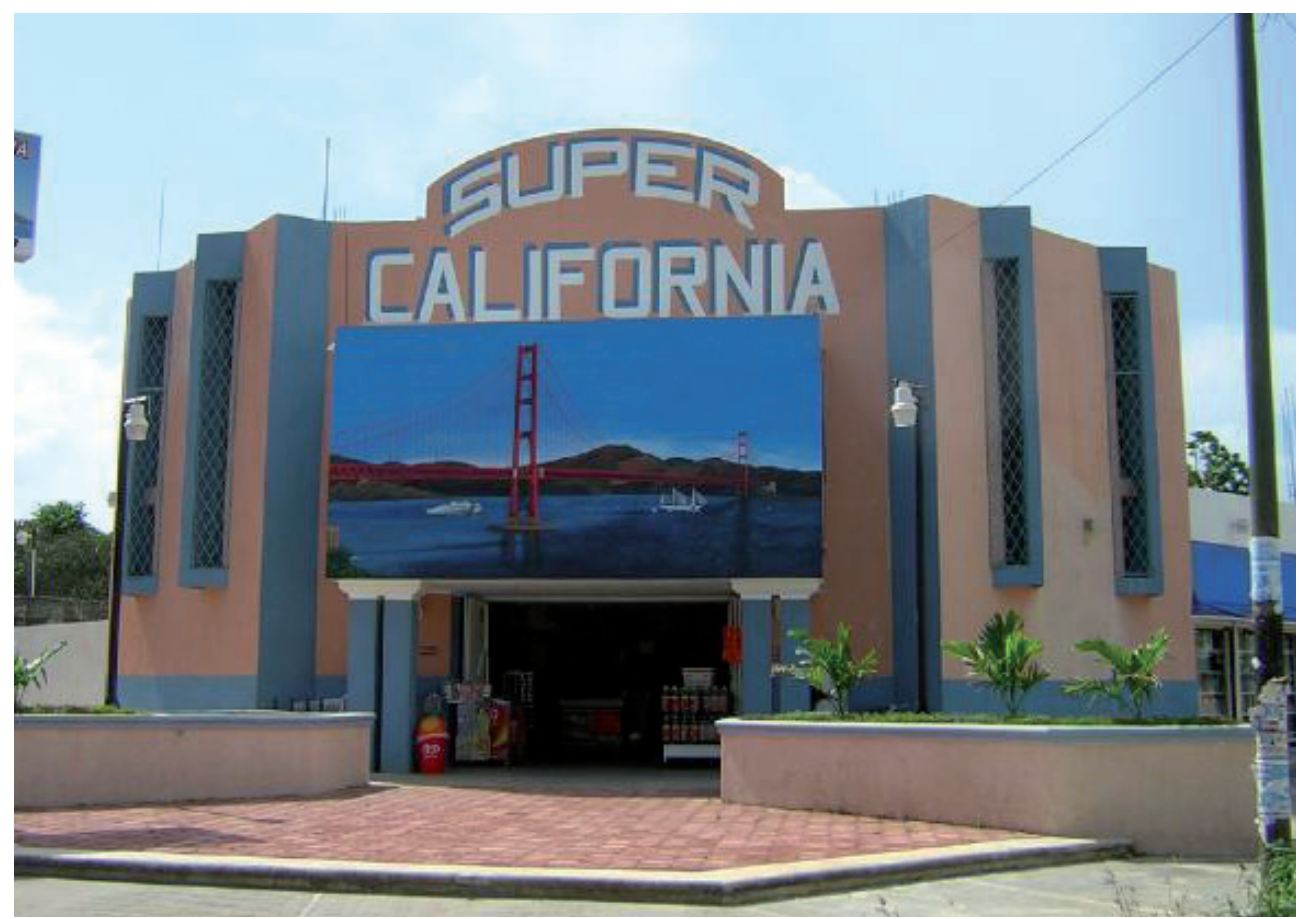

Figura 5. Super-Bodega Oxcutzcab, Yucatán 
tienen una situación económica desahogada pueden ser una fuente importante en la generación de nuevos flujos turísticos hacia México.

La interconexión entre las esferas local (la necesidad) y la global (las oportunidades) ha sido clave a la hora de comprender las estrategias que han desarrollado las familias yucatecas para afrontar el proceso de modernización forzada al que se vieron sometidas como consecuencia del desmantelamiento del estado protector en los años 80 y solo a la luz de esta reflexión pueden entenderse muchas de las formas de interrelación social que se aprecian, incluso en lugares de la península aparentemente muy alejados de la "civilización". Para comprender esta interacción ya no resulta suficiente una mirada unívoca desde una perspectiva de simples relaciones asimétricas sino que hay tener en cuenta el protagonismo adquirido por la movilidad que generan las nuevas accesibilidades físicas y psicológicas, como los servicios aéreos.

Los ejemplos citados antes muestran cómo en la península de Yucatán la interacción escalar es un factor cotidiano y cómo la mirada interdisciplinar resulta clave en su comprensión. A pesar de quienes se esfuerzan en reivindicar la pervivencia y la pureza de "lo maya" desde la perspectiva local, actualmente no existe en toda la península una sola localidad que no haya sido tocada por lo que hemos llamado el "espíritu Cancún": sea en forma de emigración selectiva (primero hombres, después mujeres; primero hacia Cancún y otras localidades de la Riviera o hacia Mérida, después hacia otras partes del país o hacia el extranjero); sea en forma de remesas de emigrantes; sea en forma de turismo convencional o de turismos cada vez más difusos.

Este "espíritu" puede interpretarse como una especie de oleada que ha imbuido de modernidad a todas las esferas de lo económico y lo social como consecuencia de la inserción de Yucatán en los procesos globales intensificada a raíz de la creación en 1975 del polo de desarrollo turístico de Cancún en el extremo nororiental de la península, literalmente "en medio de la nada". Desde entonces, los cambios en la articulación regional han sido drásticos: peso creciente de Cancún en un sistema urbano secularmente regido (y monopolizado) por Mérida con quien empieza a competir como metrópoli de equilibrio; desbordamiento de la actividad turística colonizando el frente costero que hoy constituye la Riviera Maya; gravitación demográfica hacia los lugares impactados por las corrientes turísticas que emanan desde la Riviera (principalmente zonas arqueológicas o con arquitectura colonial); desbrozamiento de nuevos territorios (con sus sociedades y sus culturas) para solaz de actividades turísticas cada vez más nuevas aunque lo novedoso solo sea el sello de la sostenibilidad otorgado por las instituciones, nacionales o internacionales, oportunas.

De forma paralela a esta rearticulación regional, geográfica, inducida por el turismo, hemos asistido a la convulsión de las estructuras sociales y productivas, esta vez de la mano de las migraciones: cambios en la estructura socio-profesional con acusada terciarización, pero también cualificación y profesionalización crecientes; cambios en las estructuras familiares, con acusado envejecimiento de las localidades y profusión de hogares donde los abuelos quedan a cargo de los nietos; cambios en 
las cadencias laborales y de relación vecinal con fenómenos como las migraciones de retorno durante el fin de semana; cambios en las relaciones y estructuras de poder, con creciente visibilización de las mujeres, cuestionamiento de los cacicazgos tradicionales y emergencia de nuevos liderazgos tanto sociales (padrinazgo de eventos, por ejemplo) como políticos... Todo ello sin referirnos a lo más evidente: el cambio de hábitos, a menudo dramático, en un mundo que parecía "perdido" hace solo unas décadas.

La experiencia de Yucatán, sin duda extrapolable a otras regiones de México, refleja, en definitiva, la realidad de un laboratorio de análisis social donde solamente caben razonamientos interdisciplinares y multi-escalares teniendo en cuenta que quienes manejan los hilos de la urdimbre local son gentes, capitales, ideas e intereses que viven o se fraguan muy lejos. El transporte aéreo es sin duda un indicador macro, pero fidedigno, que nos pone en la pista del alcance global de estos problemas.

\section{Conclusiones}

En la introducción de este trabajo planteamos algunas reflexiones que abogaban por el diálogo interdisciplinar en el entendimiento de los procesos de globalización. En la perspectiva geográfica desde la que escribimos estas páginas, consideramos que el estudio de muchas prácticas sociales puede quedar descontextualizado sin el entendimiento del papel que juegan en ellas el espacio y las dinámicas territoriales.

El análisis de los patrones de movilidad aérea de México, expuesto en las líneas anteriores, ha puesto de manifiesto la utilidad de ciertas metodologías de carácter cuantitativo, orientadas fundamentalmente a visualizar la movilidad, para aprehender dinámicas territoriales y socio-culturales de orden global, y para apreciar los roles que desempeñan los lugares y las regiones en las configuraciones territoriales que derivan de ellas.

De esta forma, sugerimos que los análisis de conectividad aérea, tradicionalmente confinados al ámbito de la Geografía, constituyen un eslabón importante para entender, por ejemplo, procesos y negociaciones culturales en lugares concretos donde la movilidad - a través de las migraciones o del turismo- es un elemento esencial de la identidad territorial. En este sentido, el reconocimiento de roles en los lugares y en las regiones, el conocimiento de la procedencia geográfica y social de las innovaciones socio-culturales, de las dimensiones que tienen los vectores que las producen (frecuencias de transporte, volumen de emigrantes, turistas, viajeros ...) y de las escalas en que se desarrollan, son procesos que se pueden visibilizar a través de los análisis de conectividad aérea.

Durante mucho tiempo el transporte aéreo ha sido interpretado como un vehículo de modernidad y de internacionalidad. Posteriormente el avión se ha consolidado como un medio fundamental para el desenclave de lugares remotos o de accesibilidad difícil y de regiones cuyos niveles de desarrollo económico no hacían rentable las redes de transporte superficial. Desde hace ya varias décadas, el transporte aéreo es uno de los vectores de la globalización con el que se transportan no solo 5.000 
millones de pasajeros, sino con el que también viajan sus modos de vida, sus ideas y sus expectativas sobre los lugares que visitan o sobre los que se asientan.

Al abordar con estudios de detalle, como ha sido el caso de México, el análisis de las pautas de movilidad asociadas al transporte aéreo se ha revelado la existencia de ciudades y localidades cuyas funciones territoriales se han visto alteradas como consecuencia de su necesaria adaptación a las nuevas dinámicas globales. Ante todo, se ha puesto de manifiesto que Ciudad de México, que es el nodo crucial de la inserción del país en los circuitos internacionales, ocupa un rango importante, pero secundario, dentro de un supuesto sistema de ciudades mundiales rectoras. En segundo lugar, se ha revelado el protagonismo que han adquirido las ciudades turísticas en el escenario internacional del transporte aéreo, y que tiene como exponente sobresaliente el caso de Cancún. El análisis de la conectividad aérea ha puesto de manifiesto cómo los territorios turísticos surgen a veces, y en parte gracias a la accesibilidad que el transporte aéreo les confiere, con una absoluta ausencia de integración en sus contextos nacionales.

En tercer y último lugar, el análisis de la conectividad aérea ha permitido plantear que la penetración de la población emigrante mexicana en Estados Unidos, apreciable en la diversidad de rutas y en las altas frecuencias de conexión, debe entenderse como un proceso de ida y vuelta. En este sentido, los "clanes familiares", identificados por la industria del transporte aéreo como usuarios principales de sus servicios, constituyen modelos novedosos de interacción social que sin duda están modificando territorios y patrones culturales tanto en las zonas de llegada de los emigrantes como en las zonas de origen. En esta perspectiva y para comprender la tremenda complejidad de los procesos actuales de hibridación y el sentido de conceptos novedosos como el de la glocalización, no solo resulta imprescindible contemplar las remesas de divisas que contribuyen al sostenimiento de las familias sino también aprehender los hábitos, costumbres y modas extranjeras que se conectan más que a través de las redes virtuales, por medio del encuentro cara a cara entre las personas.

Con el ejemplo desarrollado en estas páginas hemos tratado de mostrar algunas perspectivas geográficas para valorar la magnitud de los procesos y los cambios relacionados con unas condiciones de aceleración creciente de la movilidad. Pero una perspectiva geográfica aislada, centrada solo en los aspectos estrictamente territoriales y que a menudo se aborda con metodologías cuantitativas excluyentes, deriva a menudo en marcos explicativos demasiado constreñidos para comprender los procesos de orden socio-cultural que alimentan y que a su vez son generados por los procesos globalizadores allí donde la movilidad es un factor determinante. 


\section{Anexo de cuadros}

Cuadro 1. Conectividad internacional de México según áreas geográficas en 1970 y 2008

\begin{tabular}{|c|c|c|c|c|c|c|c|c|c|c|c|c|c|c|}
\hline & \multicolumn{2}{|c|}{$E \boldsymbol{E U U}$} & \multicolumn{2}{|c|}{$C A N A D A$} & \multicolumn{2}{|c|}{ CARIBE } & \multicolumn{2}{|c|}{ SUDAMERICA } & \multicolumn{2}{|c|}{ EUROPA } & \multirow{2}{*}{$\begin{array}{c}\text { PACIFICO } \\
\text { F }\end{array}$} & \multicolumn{3}{|c|}{ TOTAL } \\
\hline & $\mathbf{F}$ & $\mathbf{N}$ & $\mathbf{F}$ & $\mathbf{N}$ & $\mathbf{F}$ & $\mathbf{N}$ & $\mathbf{F}$ & $\mathbf{N}$ & $\mathbf{F}$ & $\mathbf{N}$ & & $\mathbf{N}$ & $\mathbf{F}$ & $\mathbf{N}$ \\
\hline 1970 & 665 & 25 & 12 & 5 & 119 & 14 & 56 & 11 & 30 & 7 & 3 & 3 & 885 & 65 \\
\hline 2008 & 9298 & 51 & 320 & 5 & 763 & 9 & 377 & 7 & 458 & 12 & 34 & 2 & 11250 & 86 \\
\hline \multicolumn{15}{|c|}{ Número de nodos mexicanos conectados con cada sub-sistema } \\
\hline 1970 & \multicolumn{2}{|c|}{14} & \multicolumn{2}{|c|}{1} & \multicolumn{2}{|c|}{3} & \multicolumn{2}{|c|}{1} & \multicolumn{2}{|c|}{3} & 2 & \multicolumn{3}{|c|}{14} \\
\hline 2008 & \multicolumn{2}{|c|}{33} & \multicolumn{2}{|c|}{8} & & & \multicolumn{2}{|c|}{2} & \multicolumn{2}{|c|}{3} & 2 & \multicolumn{3}{|c|}{33} \\
\hline
\end{tabular}

NOTA: $\mathrm{F}=$ Frecuencias semanales de vuelo. $\mathrm{N}=$ nodos de cada subsistema conectados con nodos mexicanos.

FUENTE: ABC World Airways y OAG International

Cuadro 2. Selección de los principales nodos del sistema latinoamericano de conectividad internacional en 1970, 1991 y 2008

\begin{tabular}{|c|c|c|c|c|c|c|c|c|c|c|c|c|c|}
\hline & \multicolumn{2}{|c|}{1970} & \multicolumn{2}{|c|}{1991} & \multicolumn{2}{|c|}{2008} & & \multicolumn{2}{|c|}{1970} & \multicolumn{2}{|c|}{1991} & \multicolumn{2}{|c|}{2008} \\
\hline & $\mathbf{C K}^{\mathrm{P}}$ & $\mathbf{J}$ & $\mathbf{C K}^{\mathrm{P}}$ & $\mathbf{J}$ & $\mathbf{C K}^{\mathrm{P}}$ & $\mathbf{J}$ & & $\mathbf{C K}^{\mathrm{P}}$ & $\mathbf{J}$ & $\mathbf{C K}^{\mathrm{P}}$ & $\mathbf{J}$ & $\mathbf{C K}^{\mathrm{P}}$ & $\mathbf{J}$ \\
\hline Ciudad de México & 5,17 & 1 & 3,49 & 4 & 3,80 & 1 & Río de Janeiro & 3,54 & 9 & 4,18 & 1 & 1,66 & 18 \\
\hline Santiago de Chile & 4,56 & 2 & 2,73 & 8 & 2,62 & 9 & Acapulco & 1,39 & 24 & - & - & - & - \\
\hline Buenos Aires & 4,5 & 3 & 3,21 & 6 & 3,26 & 4 & Mérida & 0,81 & 37 & - & - & - & - \\
\hline Caracas & 3,90 & 4 & 3,93 & 2 & 2,98 & 6 & Guadalajara & 0,60 & 47 & 0,63 & 49 & 1,14 & 27 \\
\hline Lima & 3,71 & 5 & 2,83 & 7 & 1,87 & 13 & La Habana & 0,92 & 31 & 2,72 & 9 & 2,10 & 11 \\
\hline Sao Paulo & 3,69 & 6 & 3,93 & 3 & 3,47 & 3 & Cancún & - & - & 1,33 & 28 & 3,60 & 2 \\
\hline Panamá & 3,69 & 6 & 2,63 & 10 & 3,05 & 5 & Puerto Vallarta & - & - & 0,73 & 46 & 1,10 & 29 \\
\hline San Juan Pto.Rico & 3,57 & 8 & 3,40 & 5 & 2,91 & 7 & Los Cabos & - & - & - & - & 1,33 & 22 \\
\hline
\end{tabular}

NOTA: $\mathrm{CK}^{\mathrm{p}}=$ Coeficiente de conexión ponderado. Se aplica una corrección al CK normal atendiendo al ámbito geográfico de la direccionalidad de las relaciones. Obsérvese que la disminución aparente del valor se debe a la creciente participación de nodos en el sistema de relaciones (1248 en 1970; 1446 en 1991 y 1632 en 2008). J = posición en la jerarquía del sistema latinoamericano. FUENTE: Córdoba y Gago, 2010. 
Cuadro 3. Diversificación internacional de destinos a partir de los principales nodos mexicanos

\begin{tabular}{|c|c|c|c|c|c|c|c|c|c|c|c|c|}
\hline & \multicolumn{2}{|c|}{ AM.NORTE } & \multicolumn{2}{|c|}{ AM.LAT } & \multicolumn{2}{|c|}{ EUROPA } & \multicolumn{2}{|c|}{ AS-PAF } & \multicolumn{2}{|c|}{ TOTAL } & \multicolumn{2}{|c|}{$\mathrm{CKi}$} \\
\hline & 70 & 08 & 70 & 08 & 70 & 08 & 70 & 08 & 70 & 08 & 70 & 08 \\
\hline Ciudad de México & 28 & 32 & 24 & 15 & 7 & 7 & 3 & 2 & 62 & 56 & 95,4 & 65,1 \\
\hline Guadalajara & 6 & 19 & 0 & 1 & 1 & 0 & 0 & 0 & 7 & 20 & 10,8 & 23,2 \\
\hline Monterrey & 4 & 10 & 0 & 0 & 0 & 2 & 0 & 0 & 4 & 12 & 6,2 & 13,9 \\
\hline Cancún & 0 & 37 & 0 & 5 & 0 & 10 & 0 & 0 & 0 & 52 & 0 & 60,5 \\
\hline Los Cabos & 0 & 22 & 0 & 0 & 0 & 0 & 0 & 0 & 0 & 22 & 0 & 25,6 \\
\hline Vallarta & 4 & 19 & 0 & 0 & 0 & 0 & 0 & 0 & 4 & 19 & 6,2 & 22,1 \\
\hline Acapulco & 8 & 6 & 2 & 0 & 1 & 0 & 2 & 0 & 11 & 6 & 16,9 & 7,0 \\
\hline Mérida & 4 & 2 & 6 & 0 & 0 & 0 & 0 & 0 & 10 & 2 & 15,4 & 2,3 \\
\hline Tijuana & 1 & 0 & 0 & 0 & 0 & 0 & 0 & 2 & 1 & 2 & 1,6 & 2,3 \\
\hline
\end{tabular}

FUENTE: ABC World Airways y OAG International

Cuadro 4. Conexiones internacionales a partir de otros nodos mexicanos

NOTA: $\mathrm{F}=$ Frecuencias semanales de vuelo. $\mathrm{N}=$ nodos de cada subsistema conectados con nodos

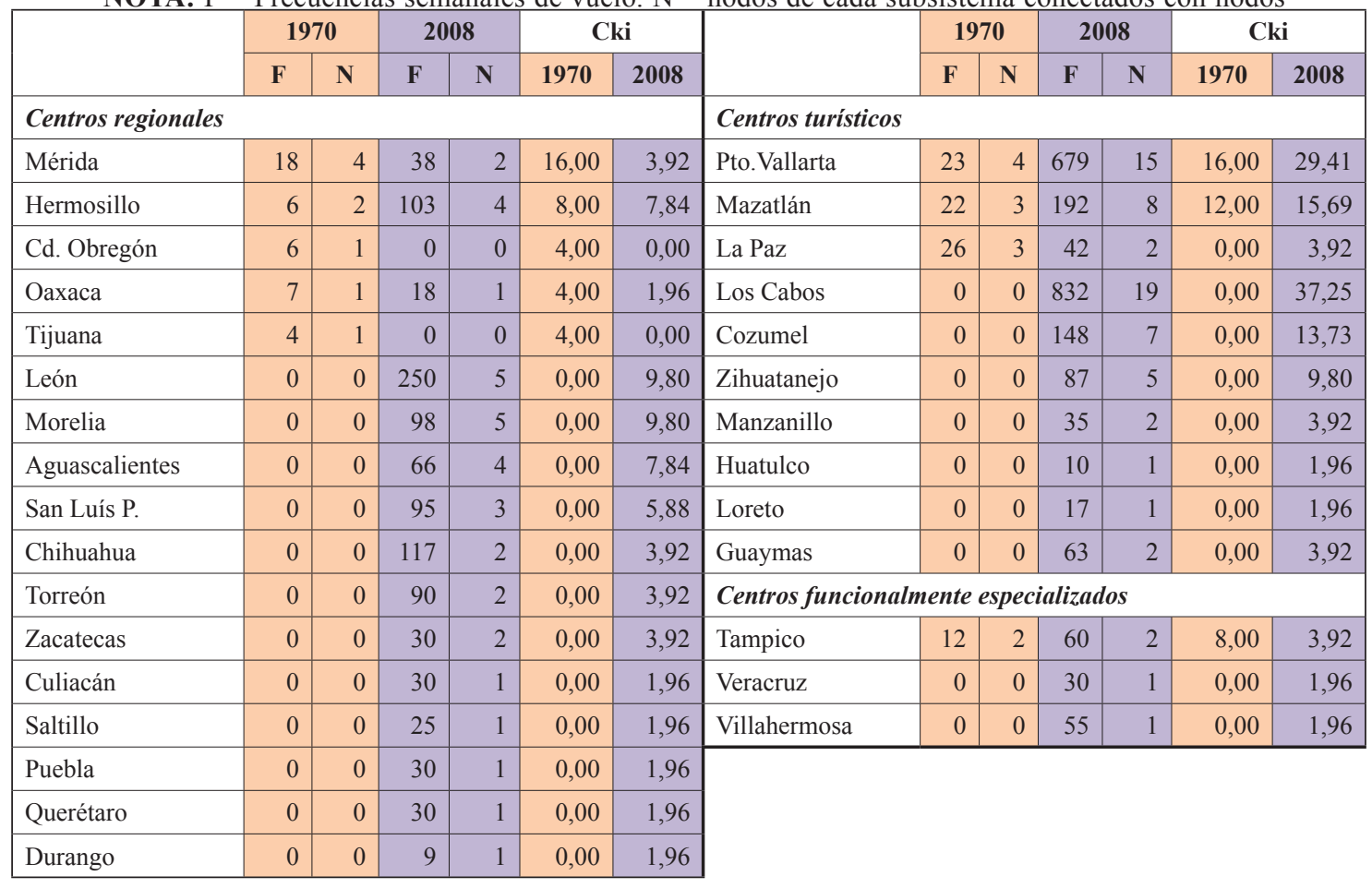

mexicanos. $\mathrm{CKi}=$ coeficiente de conexión de cada nodo.

FUENTE: ABC World Airways y OAG International 
Cuadro 5. Direccionalidad de los flujos desde ciudades de Estados Unidos hacia ciudades mexicanas en 2008

\begin{tabular}{|l|c|c|l|c|c|}
\hline & $\begin{array}{c}\text { Destinos } \\
\text { en México }\end{array}$ & $\begin{array}{c}\text { \% } \\
\text { Frecuencias }\end{array}$ & & $\begin{array}{c}\text { Destinos } \\
\text { en México }\end{array}$ & $\begin{array}{c}\text { \% } \\
\text { Frecuencias }\end{array}$ \\
\hline Houston & 27 & 19,4 & Las Vegas & 6 & 3,1 \\
\hline Los Angeles & 19 & 13,7 & Seattle & 6 & 2,8 \\
\hline Dallas/Fort Woth & 14 & 11,0 & New York & 5 & 6,6 \\
\hline Phoenix & 10 & 5,7 & San Francisco & 5 & 2,9 \\
\hline Chicago & 9 & 5,9 & Miami & 4 & 6,1 \\
\hline Atlanta & 8 & 3,5 & Otros (41) & - & 17,0 \\
\hline Denver & 6 & 2,1 & TOTAL & $\mathbf{3 5}$ & $\mathbf{1 0 0}$ \\
\hline
\end{tabular}

FUENTE: OAG International

Cuadro 6. Migración residente y direccionalidad de los flujos en zonas metropolitanas seleccionadas de Estados Unidos

\begin{tabular}{|l|r|r|r|}
\hline & $\begin{array}{c}\text { (1) } \\
\text { Residentes }\end{array}$ & $\begin{array}{c}\text { (2) } \\
\text { \% }\end{array}$ & \multicolumn{1}{c|}{$\begin{array}{c}\text { (3) } \\
\text { Frecuencias }\end{array}$} \\
\hline Los Angeles/Long Beach & 1.902 .623 & 16,5 & 14,4 \\
\hline Chicago ZM & 699.447 & 6,1 & 5,9 \\
\hline Dallas/Fort Worth & 607.180 & 5,3 & 11,0 \\
\hline Subtotal & 3.209 .250 & 27,9 & 31,3 \\
\hline
\end{tabular}

NOTA: Población nacida en México residente en el área metropolitana. Porcentaje respecto a la población nacida en México residente en Estados Unidos. Datos estimados para 2006. Porcentaje de las frecuencias de vuelo respecto al total de frecuencias semanales entre México y Estados Unidos FUENTES: Batalova, J. Migration Information Source, 2008 
Cuadro 7. Direccionalidad de los flujos desde ciudades de Estados Unidos hacia ciudades mexicanas en 2008

\begin{tabular}{|l|r|c|c|c|c|}
\hline & $\begin{array}{c}\text { (1) } \\
\text { Residentes }\end{array}$ & $\begin{array}{c}(\mathbf{2}) \\
\mathbf{\%}\end{array}$ & $\begin{array}{c}(\mathbf{3}) \\
\text { Turistas }\end{array}$ & $\begin{array}{c}(\mathbf{4}) \\
\text { Mexicanos }\end{array}$ & $\begin{array}{c}\text { (5) } \\
\text { Frecuencias }\end{array}$ \\
\hline California & 4.396 .435 & 38,1 & 14,75 & 24,52 & 21 \\
\hline Texas & 2.339 .715 & 20,3 & 19,94 & 35,37 & 32 \\
\hline Illinois & 724.845 & 6,3 & 7,44 & 14,09 & 5,9 \\
\hline Arizona & 608.645 & 5,3 & 3,05 & 35,58 & 5,7 \\
\hline Florida & 303.345 & 2,6 & 3,8 & 7,26 & 7,66 \\
\hline Georgia & 276.494 & 2,4 & $\mathrm{sd}$ & $\mathrm{sd}$ & 3,5 \\
\hline Colorado & 254.844 & 2,2 & $\mathrm{sd}$ & $\mathrm{sd}$ & 2,1 \\
\hline North Carolina & 254.830 & 2,2 & $\mathrm{sd}$ & $\mathrm{sd}$ & 1,8 \\
\hline New York & 230.999 & 2,0 & 4,64 & 5,05 & 6,6 \\
\hline Nevada & 230.314 & 2,0 & $\mathrm{sd}$ & $\mathrm{sd}$ & 3,3 \\
\hline Otros & 1.920 .938 & 16,7 & 44,96 & 8,62 & 10,4 \\
\hline TOTAL & 11.541 .404 & 100 & 100 & 19,93 & 100 \\
\hline
\end{tabular}

(1) Población residente nacida en México. (2) Porcentaje respecto a la población nacida en México residente en Estados Unidos. (3) Porcentaje del turismo internacional llegado por vía aérea a México procedente de Estados Unidos en 2000-10. (4) Porcentaje de mexicanos residentes en Estados Unidos respecto al total de turistas llegados a México desde ese país en 2000-10. (5) Porcentaje de las frecuencias de vuelo respecto al total de frecuencias semanales entre México y Estados Unidos.

FUENTE: OAG International y Batalova, 2008

\section{Referencias bibliográficas}

ABC WORLD AIRWAYS

1970; 1991 ABC World Airways Guide. Marzo, 1971, Mayo 1991. Dunstable: Reed Travel Group.

AMADEUS

2005 Future Traveller Tribes, Las tribus viajeras del mañana, 2020. Henley Centre Headlight Vision. http://www.amadeus.com/amadeus/travellertribes.html

AUGÉ, Marc

1995 Los no lugares. Una antropología de la sobremodernidad. Barcelona: Gedisa.

BANCO DE MÉXICO

2011 La Balanza de Pagos en 2010. México D.F.: Banco de México.

BATALOVA, Jeanne

2008 "Mexican Inmigrants in the United States". Migration Policy Institute, US in Focus, 4: $1-6$. 
BAUMAN, Zygmunt

2001 La Globalización: Consecuencias humanas. Ciudad de México: F. de Cultura Económica.

BE RAMÍREZ, Pedro A.

2011 "Dimensiones culturales e identidades situadas: la herencia maya en inmigrantes yucatecos a Estados Unidos". Estudios de cultura maya, XXXVIII: 167-192.

BIANET CASTELLANOS, M.

2010 A return to servitude. Maya migration and the tourist trade in Cancun. Minneapolis: University of Minnesota Press.

COLL, Atlántida; CÓRDOBA, Juan

2006 "La globalización y el sector servicios en México". Investigaciones Geográficas, 61: 114-131.

CONSONY, Eliana; TAYLOR, Peter J.

2007 "Gateway cities: círculos bancarios, concentración y dispersión en el ambiente urbano brasileño”. EURE (Santiago), Vol. 33, 100: 115-133.

CPT-CONSEJO DE PROMOCIÓN TURÍSTICA

2011 Situación del Sector Turístico. México D.F.: Secretaría de Turismo.

CÓRDOBA AZCÁRATE, Matilde

2010 "Contentiuos hotspots. Ecotourism and the Reestructuring of place at the Biosphere Reserve Ria Celestun”. Tourist Studies. Vol., 10 (2): 99-116

CÓRDOBA, Juan; CÓRDOBA, Matilde; GAGO, Cándida; SERRANO, Milagros.

2007a "Turismo y desarrollo: la eterna controversia a través del caso de Cancún”, en A. García Ballesteros y García Amaral, Un mundo de ciudades. Procesos de urbanización en México en tiempos de Globalización. Barcelona: GEDISA, 189-209.

CÓRDOBA, Juan; GAGO, Cándida

2002 "Madrid en el escenario de un sistema mundial de ciudades". Anales de Geografía de la Universidad Complutense, Vol. Extraordinario: 203-219.

2011 "Latin American Cities and Globalisation: Change and Permanency in the Context of Development Expectations". Urban Studies, 47(9): 2003-2021.

CÓRDOBA, Juan; GAGO, Cándida; SERRANO, Milagros

2007 b "Transporte aéreo y espacialidad diferencial”, en S. Gutiérrez y J. J. Sanz (eds.), Homenaje al Profesor José Manuel Casas Torres, Madrid: Universidad Complutense de Madrid, 45-64.

CORNEJO, Inés; FORTUNY, Patricia

2012 "Liminalidad social y negociación cultural: inmigrantes yucatecos en San Francisco, California”. Convergencia, Revista de Ciencia Sociales, 19-58: 71-96. 
DERUDDER, Ben

2006 "On Conceptual Confusion in Empirical Analyses of a Transnational Urban Network". Urban Studies, 43 (11): 2027-2046.

DERUDDER, Ben; WITLOX, Frank

2005 "An appraisal of the use of airline data in assessments of the world city network". Urban Studies, 42(13): 2371-2388.

DERUDDER, Ben; TAYLOR, Peter, J.; WITLOX, Frank; et al.

2003 "Hierarchical tendencies and regional patterns in the world city network: a global urban analysis of 234 cities". Regional Studies, 37(9): 875-886.

Diario de Yucatán

2011 "Habrán 165 mil yucatecos residiendo en Estados Unidos al cierre del 2011". Publicado el 25 diciembre 2011. Consultado el 27 abril 2012 en http://v7.yucatan. com.mx/20/nota-10/

ESCOBAR, Arturo

2008 Territories of difference. Place, movements, life, redes. Durham and London: Duke University Press.

FIGUEROA, Ma Elena

2009 "Los otros turistas. Reflexiones en torno al turismo que hacen los migrantes". Topofilia, Revista de El Colegio de Sonora, 1-3: 1-6.

FORER, Pip

1978 "A place for Plastic Space”. Progress in Human Geography, (2) 2: 230-267.

FRIEDMAN, John

1986 "The world city hypothesis". Development and Change, 17: 69-83.

1995 "Where we stand: A decade of world city research", en Knox y Taylor (eds.), World Cities in a World System. Cambridge: Cambridge U. Press, 436-457.

GAGO, Cándida

2003 Región, Política, Transporte Aéreo. Madrid: Universidad Complutense de Madrid.

GARCÍA CANCLINI, Néstor

1989 Culturas híbridas. México D.F.: Grijalbo.

GILBERT, Alan

1998 "World Cities and the urban future: the view from Latin America", en Lo y Yeung (eds.), Globalization and the World Large Cities. Tokio: United Nations Universtiy Press.

HARVEY, David

1983 Teorías, leyes y modelos en Geografía. Madrid: Alianza Editorial.

1998 La condición de la postmodernidad: investigación sobre los origenes del cambio cultural. Buenos Aires: Amorrortu. 
INEGI

1991 XI Censo de Población y Vivienda 1990. Aguascalientes: Instituto Nacional de Estadística y Geografía.

2001 XII Censo de Población y Vivienda 2000. Aguascalientes: Instituto Nacional de Estadística y Geografía.

2006 II Conteo de Población y Vivienda 1990. Aguascalientes: Instituto Nacional de Estadística y Geografía.

2011a Anuario Estadístico de los Estados Unidos Mexicanos. Aguascalientes: Instituto Nacional de Estadística y Geografía.

2011b Censo de Población y Vivienda 2010. Aguascalientes: Instituto Nacional de Estadística y Geografía.

LARSEN, Jonas; URRY, John; AXHAUSEN, Kay

2006 Mobilities, Networks, Geographies. Aldershot: Ashgate

LELÉ, Sharachchandra; NORGAAR, Richard B.

2005 "Practicing interdisciplinarity", Special Roulndtable Section. BioScience, Vol. 55, 11: 967-975.

MCGREW, Tony

1992 “Global Society?”. En Hall, Held y Mcgrew (eds.), Modernity and its Futures. Cambride: Polity Press, 61-102.

MORAN, Michael

2006 "Interdisciplinarity and Political Science". Politics, Vol. 26(2): 73-83.

OAG INTERNATIONAL

2008 World flights Database (All flights, to/from all airports worldwide). Manchester. Base de datos adquirida en 2008.

RAMÍREZ, Roberto; DE LA CRUZ, Patricia

2003 "The Hispanic Population in the United States". Current Population Reports, P20545. Washington DC: U.S. Census Bureau.

REYES, Manuel

2008 El flujo migratorio internacional de México hacia los Estados Unidos. México D.F.: Centro de Documentación, Información y Análisis de la Cámara de Diputados.

SASSEN, Saskia

1991 The Global City: New York, London, Tokyo. Princeton: Princeton University Press.

SCHOENBERGER, Erica

2001 "Interdisciplinarity and social power". Progress in Human Geography, 25, 3: $365-382$

SECTUR

2012 Estadísticas más recientes de la actividad del sector turismo. Reporte ejecutivo de la Subsecretaría de Planeación Turística. México, D.F.: Secretaría de Turismo. 
SOLÍS, Mirian; FORTUNY, Patricia

2010 "Otomíes hidalguenses y mayas yucatecos. Nuevas caras de la migración indígena y viejas formas de organización”. Migraciones Internacionales, 5-4: 101-138.

TAYLOR, Peter, J.; NI, P.; DERUDDER, Ben; HOYLER, Michael

2011 Global Urban Analysis: a Survey of Cities in Globalization. London: Earthscan.

TOMLINSON, John

2001 Globalización y Cultura. México D.F.: Oxford University Press.

TORRES, Rebecca; MOMSEN, Janet

2005 "Gringolandia. The construction of a new tourist space in Mexico". Annals of the American Association Geographers, )5-2: 314-335.

URRY, John.

2001 "Globalising the Tourist Gaze", Cityscapes Conference. Graz November 2001. http://www.lancs.ac.uk/fass/sociology/papers/urry-globalising-the-tourist-gaze.pdf.

2007 Mobilities. Cambridge: Polity Press.

WALLACE, Steven, P.; CASTAÑEDA, Xóchitl

2006 "Perfil Socio-Demográfico de los inmigrantes mexicanos en Estados Unidos". Hoja de Datos de la Iniciativa de Salud de las Américas. Berkeley: University of California. 